\title{
Capital humano e empreendedorismo como forma de alcance dos direitos sociais
}

\author{
Human capital and entrepreneurship as a means of reaching social rights
}

André Luís Cateli Rosa*

Jussara Suzi Assis Borges Nasser Ferreira ${ }^{* *}$

\section{REFERÊNCIA}

ROSA, André Luís Cateli; FERREIRA, Jussara Suzi Borges Nasser. Capital humano e empreendedorismo como forma de alcance dos direitos sociais. Revista da Faculdade de Direito da UFRGS, Porto Alegre, n. 42, p. 150-171, abr. 2020. DOI: <https://doi.org/10.22456/0104-6594.77477>.

\section{RESUMO}

No presente artigo aborda-se a ineficiência do Estado para assegurar os direitos sociais a todos os seus cidadãos, o que é referendado pelo ordenamento jurídico por meio da invocação da teoria da reserva do possível. Diante desse contexto, objetiva apontar outros meios de viabilização e concretização desses direitos com o fim de assegurar a igualdade e a dignidade da pessoa humana. Assim, na busca do alcance dos direitos sociais, contextualiza a teoria do capital humano, colocando-a como alternativa por meio do desenvolvimento do empreendedorismo. Destarte, a criteriosa revisão de literatura e pesquisa jurisprudencial demonstram a relevância do estudo dirigido à efetividade dos direitos sociais. Tais direitos, de cunho fundante, são apresentados na investigação, vinculados à apreensão da teoria da reserva do possível, à noção de capital humano e ao empreendedorismo. A interpretação de tal conjunto, núcleo vital deste estudo, indica as condições de possibilidade, para concretização dos direitos sociais. Por fim, verifica-se que a teoria da pedagogia empreendedora, que propõe direcionamento de esforços do Estado na educação e formação das pessoas, com o propósito de desenvolver uma cultura empreendedora, seria capaz de colocar todos em um patamar de igualdade de condições, proporcionando autonomia e liberdade de escolha para o desenvolvimento de suas próprias atividades, o que possibilitaria o alcance dos direitos sociais por meio dos próprios esforços.

\section{PALAVRAS-CHAVE}

Direitos sociais. Capital humano. Empreendedorismo.

\begin{abstract}
This article addresses the inefficiency of the State to ensure social rights to all its citizens, which is endorsed by the legal system and invoking the theory of the reserve of the possible. In view of this context, it is necessary to point out other ways of making these rights feasible and concrete in order to ensure the equality and dignity of the human person. Thus, in the search for the reach of social rights, it contextualizes the theory of human capital, placing it as an alternative through the development of entrepreneurship. Thus, the careful review of literature and jurisprudential research demonstrate the relevance of the study directed to the effectiveness of

\footnotetext{
${ }^{\star *}$ Doutorando em Direito pela Universidade de Marília - UNIMAR. Mestre em Teoria de Direito e do Estado pela Fundação de Ensino Eurípides Soares da Rocha - UNIVEM (2007). Educador e Assessor Jurídico do Banco do Brasil S/A. Advogado e Administrador. Especialista em Liderança e Coaching para Gestão de Pessoas. Professor dos Cursos de Administração e Ciências Contábeis das Faculdades Integradas de Ourinhos - FIO. Email: contato@professorcateli.com.br. Web site http://www.professorcateli.com.br.

${ }^{* * * \star}$ Doutora em Direito das Relações Sociais pela Pontifícia Universidade Católica de São Paulo - PUC (1993); Mestre em Direito pela Universidade Estadual de Londrina - UEL (1984); Bacharel em Direito pela Universidade Estadual de Londrina. Advogada. Atualmente é professora permanente do Programa de Doutorado e Mestrado em Direito da Universidade de Marília; professora permanente do Programa de Doutorado e Mestrado da Universidade Paranaense e professora colaboradora do Programa de Mestrado em Direito Universidade Estadual de Londrina - UEL. E-mail jussara@bflaw.adv.br.
} 
social rights. These rights, of a founding nature, are presented in the investigation, linked to the apprehension of the theory of the reserve of the possible, to the notion of human capital and entrepreneurship. The interpretation of such a set, the vital nucleus of this study, indicates the conditions of possibility for the realization of social rights. Finally, it is verified that the theory of entrepreneurial pedagogy, which proposes directing the efforts of the State in the education and training of people, with the purpose of developing an entrepreneurial culture, would be able to put everyone on a level-playing field, providing autonomy and freedom of choice for the development of their own activities, which would enable the achievement of social rights through their own efforts.

\section{KEYWORDS}

Social rights. Human capital. Entrepreneurship.

\section{SUMÁRIO}

1. Introdução. 2. Direitos sociais. 3. A teoria da reserva do possível. 4. A teoria do capital humano. 5. Capital humano nas organizações. 6. Empreendedorismo como forma de alcance dos direitos sociais. 7. Conclusão. Referências. Dados da publicação.

\section{INTRODUÇÃO}

Os direitos sociais, contidos dentre os direitos e garantias fundamentais, são aqueles dos quais decorre obrigação positiva do Estado para a sua concretização, inseridos nos direitos fundamentais de segunda geração. No Brasil, estão prescritos em sua maior parte no art. $6^{\circ}$ da Constituição Federal de 1988, refletindo na posição do Estado em garantir a igualdade e a dignidade da pessoa humana para seus cidadãos.

Destacam-se entre os direitos sociais abarcados pela Constituição Federal de 1988: a educação, a saúde, a alimentação, o trabalho, a moradia, o transporte, o lazer, a segurança, a previdência social, a proteção à maternidade e à infância e a assistência aos desamparados.

Todavia, para que o Estado possa disponibilizar esses direitos aos cidadãos, é necessária a existência de disponibilidade financeira, o que não ocorre em função do constante desequilíbrio no qual persistem as contas públicas, de forma que não se registra na história do país qualquer momento de satisfatória provisão financeira para que se promovessem esses direitos, com a dignidade que a carta política prescreve.

Não bastasse tal situação, o ordenamento jurídico pátrio importou do direito germânico o princípio reserva do possível, segundo o qual o Estado somente é obrigado a entregar os direitos sociais aos seus cidadãos desde que aqueles sejam razoáveis e haja disponibilidade financeira para tanto. Tal situação legitima ao Estado o não cumprimento de seus deveres no que tange a esses direitos fundamentais de segunda geração, que envolvem prestações positivas de sua parte. 
Levando-se em consideração que não é possível a entrega efetiva dos direitos sociais pelo Estado, por meio de prestações positivas que busquem a igualdade e a dignidade da pessoa humana, em função principalmente da inexistência de recursos financeiros, parece apropriado questionar: não há outros meios de viabilizar a concretização desses direitos aos cidadãos? Não existem outras formas de assegurar a igualdade e a dignidade da pessoa humana?

Desta forma, a necessidade de garantir os direitos sociais aos cidadãos, como instrumento de efetivação do princípio da igualdade e da dignidade da pessoa humana, que são pilares da Constituição Federal e do próprio Estado Democrático de Direito, justifica um estudo aprofundado sobre o tema, com o intuito de demonstrar que referidos direitos podem ser alcançados pela população por outros meios, que não só pela prestação positiva do Estado em relação a todos eles, mas através de sua conquista por meio do esforço e trabalho de cada um, tendo por base a prestação positiva e adequada do Estado em relação a pelo menos um deles: a educação.

Destarte, uma criteriosa revisão de literatura e uma pesquisa jurisprudencial foram preceitos básicos de um estudo que perseguiu o viés da efetividade dos direitos sociais, de cunho introdutório, conceitual e fundante, até o atual cenário nacional, com destaque para os direitos sociais, a teoria da reserva do possível, a concepção de capital humano e o empreendedorismo. A análise pontual de tais institutos somente cedeu espaço quando da união dos mesmos para sobejar uma proposta interpretativa, núcleo vital deste estudo. $\mathrm{O}$ raciocínio teleológico, portante, progrediu rumo à mescla destes institutos de suma importância para concretização dos direitos sociais.

Para tanto, primeiramente, são abordadas noções gerais de direitos sociais, demonstrando, na sequência, que o princípio da reserva do possível assegura ao Estado a possibilidade de seu não cumprimento.

Em continuidade, é empreendida uma abordagem da teoria do capital humano, que, aplicada às organizações, conforme demonstrado na sequência, é responsável pela geração de riqueza para as pessoas e para a nação, tudo seguido de críticas que apontam que tal situação não é capaz de extirpar as desigualdades sociais.

Finalmente, por meio da proposta interpretativa, conclui que, a partir da teoria da pedagogia empreendedora, de Fernando Dolabela, que propõe direcionamento de esforços do Estado na educação e na formação das pessoas, com o intuito de criar uma cultura empreendedora, seria capaz de colocar todos em um patamar de igualdade de condições, 
proporcionando autonomia e liberdade de escolha para o desenvolvimento de suas próprias atividades, o que possibilitaria o alcance dos direitos sociais por meio dos próprios esforços.

\section{DIREITOS SOCIAIS}

Historicamente, o avanço do capitalismo e a sedimentação da política liberal ocasionaram o crescimento das desigualdades sociais, tudo sob referendo das instituições. Nesse sentido, o constante conflito existente entre as classes dos patrões e dos operários estimulou a organização destes últimos, que passaram a exercer pressão cada vez maior frente ao Estado para que houvesse o reconhecimento de direitos que assegurassem a igualdade mínima de condições entre as pessoas, vez que de nada adiantaria ter liberdades (direitos fundamentais de primeira geração) sem garantias mínimas para seu exercício.

É nesse cenário que cresce a pressão para o reconhecimento dessas garantias por meio do ordenamento jurídico dos Estados, vez que, conforme bem contextualiza Dalmo de Abreu Dallari (2004, p. 46), "não basta afirmar que todos são iguais perante a lei; é indispensável que sejam assegurados a todos, na prática, um mínimo de dignidade e igualdade de oportunidades".

É nesse contexto então que surgem os chamados direitos sociais, hodiernamente denominados de direitos fundamentais de segunda geração, que dizem respeito aos direitos de igualdade e visam a realização da justiça social, garantindo a liberdade por intermédio do Estado.

Traduzem uma etapa de evolução na proteção da dignidade humana. Sua essência é a preocupação com as necessidades do ser humano. Garantem uma forma de proteção à dignidade humana, objetivando assegurar a satisfação das necessidades mínimas para que se tenha dignidade e sentido na vida (ARAÚJO; NUNES JÚNIOR, 1999, p. 73).

Trata-se de desdobramento da perspectiva de um Estado Social de Direito. Seu reconhecimento encontra guarida pela primeira vez na Constituição Francesa de 1791 e, posteriormente, possui como documentos marcantes a Constituição mexicana de 1917, a de Weimar, na Alemanha, de 1919, e, no Brasil, a Constituição de 1934.

Nas palavras de José Afonso da Silva (2000, p. 289):

Assim, podemos dizer que os direitos sociais, como dimensão dos direitos fundamentais do homem, são prestações positivas proporcionadas pelo Estado direta ou indiretamente, enunciadas em normas constitucionais, que possibilitam melhores 
condições de vida aos mais fracos, direitos que tendem a realizar a igualização de situações sociais desiguais. São, portanto, direitos que se ligam ao direito de igualdade. Valem como pressupostos do gozo dos direitos individuais na medida em que criam condições materiais mais propícias ao auferimento da igualdade real, o que, por sua vez, proporciona condição mais compatível com o exercício efetivo da liberdade.

Desta forma, os direitos sociais apresentam-se como prestações positivas a serem implementadas pelo Estado e tendem a concretizar a perspectiva de uma isonomia substancial e social na busca de melhores e adequadas condições de vida. Formam um conjunto de valores básicos e fins diretivos do poder público (ALMEIDA; MARTINS, 2016, p. 90).

Ingo Sarlet (2008, p. 304) destaca que os direitos sociais encontram-se intimamente ligados às tarefas de melhoria, distribuição e redistribuição dos recursos existentes, assim como à criação de bens essenciais não disponíveis para todos que deles necessitam.

Os direitos sociais são aqueles que reclamam do Estado um papel prestacional, de minoração das desigualdades sociais (ARAUJO; NUNES JÚNIOR, 1999, p. 146).

No Brasil, esses direitos encontram-se consagrados como fundamentos da República Federativa (art. 1. ${ }^{\circ}, \mathrm{IV}$, da $\mathrm{CF} / 88$ ), que assim dispõe:

Art. $1^{\circ}$. A República Federativa do Brasil, formada pela união indissolúvel dos Estados e Municípios e do Distrito Federal, constitui-se em Estado Democrático de Direito e tem como fundamentos:

[...]

IV - os valores sociais do trabalho e da livre iniciativa;

Isso porque, na esteira do raciocínio aqui desenvolvido, a livre iniciativa somente é possível uma vez que sejam assegurados os direitos sociais, o que proporciona o mínimo de condições existenciais para o ser humano.

Não obstante sua consagração, no Brasil, a Constituição Federal de 1988 trouxe de forma expressa o reconhecimento dos direitos sociais em seu capítulo II, primeiramente por meio de rol prescrito no art. $6^{\circ}$, que assim dispõe: "São direitos sociais a educação, a saúde, a alimentação, o trabalho, a moradia, o transporte, o lazer, a segurança, a previdência social, a proteção à maternidade e à infância, a assistência aos desamparados, na forma desta Constituição".

Além do caput do art. $6^{\circ}$, a Constituição Federal também abriga esses direitos em seus incisos I a XXXIV, alíneas e parágrafo único; artigo $8^{\circ}$, incisos I a VI e parágrafo único; artigo $9^{\circ}$ e parágrafos $1^{\circ}$ e $2^{\circ}$; bem como nos artigos 10 e 11 . 
Diante desse contexto, perceptível é que tais direitos demandam absoluta prestação estatal, o que torna importante e atual o debate acerca de sua eficácia e aplicabilidade, bem como a implementação de formas que tornem possível o seu alcance, não só para uma minoria, mas para toda a sociedade.

\section{A TEORIA DA RESERVA DO POSSÍVEL}

A teoria da reserva do possível tem por escopo viabilizar ao Estado justificativas aceitáveis para o não cumprimento de políticas públicas, vez que legitima que direitos constitucionais dos cidadãos, como os sociais, por exemplo, não devam necessariamente ser observados.

A primeira notícia que se tem de sua aplicação é proveniente do direito germânico, por meio de um caso julgado pela Corte Constitucional, oportunidade na qual um cidadão pleiteou uma vaga no ensino superior público, todavia, sem que tivesse que se submeter a processo seletivo, alegando que, nos termos da lei, era detentor de direito de escolha de sua profissão, motivo pelo qual não poderia o Estado the restringir acesso ao curso superior (KRELL, 2002, p. 50-52).

Na oportunidade, para solução do conflito instaurado entre o demandante e o Estado, a Corte alemã desenvolveu e aplicou pela primeira vez a teoria da reserva do possível, resolvendo que a disponibilidade de determinados serviços públicos deve ser condicionada à disponibilidade de recursos e de meios do Estado, de forma que não se mostra sensato exigir prestações que fogem do juízo de razoabilidade. Com esses fundamentos, a demanda foi julgada improcedente (SARLET, 2003, p. 264).

Referida tese ficou lá denominada de "Des Vorbehalt des Möglichen"1 que evoluiu para o princípio da reserva do possível no Brasil.

Verifica-se que, nesse julgamento pela Corte alemã, a tese da reserva do possível foi inserida como um limite ao direito à participação política do indivíduo, o que deve ser entendido como limitação ao cumprimento dos direitos sociais em função da própria escassez financeira estatal. Nesse sentido, Céline Fercot (2010, p. 82) destaca que "this reserve is the main limit fixed to the 'rights to political participation' (Teilhaberechte), that is to what the individual has the right to 'reasonably' expected to the collectivity"'.

\footnotetext{
1 "Reserva do potencial” (tradução livre).
} 
Segundo Ingo Sarlet (2003, p. 265), ao interpretar referido princípio, esclarece que, mediante sua aplicação ao caso abordado alhures, houve o entendimento da Corte Alemã de que "a prestação reclamada deve corresponder ao que o indivíduo pode razoavelmente exigir da sociedade, de tal sorte que, mesmo em dispondo o estado de recursos e tendo poder de disposição, não se pode falar em uma obrigação de prestar algo que não se mantenha nos limites do razoável".

Tem-se então que o princípio da reserva do possível foi utilizado como fundamento para restringir direitos previstos na carta política do Estado.

$\mathrm{Na}$ esteira desse entendimento, levando-se em consideração o direito positivo brasileiro, Sarlet (2009, p. 287) esclarece que esse princípio possui tríplice dimensão, a saber: i) a existência de disponibilidade fática dos recursos para a efetivação dos direitos constitucionalmente garantidos; ii) a sua disponibilidade material (orçamentária); e iii) proporcionalidade da prestação, o que deve sempre levar em conta também a razoabilidade da prestação.

Desta forma, dentre as dimensões destacadas, tem-se a limitação orçamentária como fundamento a ser suscitado para a aplicação do princípio da reserva do possível, legitimando assim a inobservância dos direitos sociais por parte do Estado sempre que não houver recursos financeiros disponíveis para tanto, ou mesmo na hipótese de inexistência de previsão orçamentária para resguardar determinado direito.

É nesse contexto que alguns autores, e o próprio Supremo Tribunal Federal, conforme será demonstrado na sequência do trabalho, mencionam esse princípio como sendo a "reserva do financeiramente possível", pois por meio dele vinculam o cumprimento das obrigações do Estado à preexistência de recursos financeiros.

Márcio Flávio Mafra Leal (1998, p. 108) também firma o entendimento de que a efetividade dos direitos sociais, por meio de políticas públicas, somente é possível caso haja disponibilidade de recursos financeiros devidamente previstos no orçamento do Estado para essa finalidade. Caso contrário, não pode o poder judiciário consentir com a destinação de qualquer recurso, mesmo que seja para garantir a efetividade de direitos sociais.

Como consequente, Ingo Sarlet (2008, p. 265) confere destaque ao princípio da razoabilidade, posicionando-se no sentido de que, segundo essa teoria, mesmo que o Estado

\footnotetext{
${ }^{2}$ A reserva é um meio de limitação estabelecida para os "direitos à participação política" (direitos fundamentais de segunda geração), isso é o que o indivíduo tem direito de razoavelmente esperar da coletividade" (tradução livre).
} 
disponha da capacidade e dos recursos necessários, mesmo tratando-se de direitos sociais, não deve haver decisões que fujam dos limites do razoável.

Tal posição doutrinária, que se vale da razoabilidade e da disposição de recursos financeiros, foi acolhida pelo Supremo Tribunal Federal quando do julgamento da $\mathrm{ADPF}^{3} \mathrm{n}$. 45, oportunidade na qual a Suprema Corte confirmou a existência e utilização da teoria da reserva do possível no ordenamento jurídico pátrio. A decisão cristalizou-se, em trecho selecionado, com o seguinte teor:

[...]Vê-se, pois, que os condicionamentos impostos, pela cláusula da "reserva do possível", ao processo de concretização dos direitos de segunda geração - de implantação sempre onerosa -, traduzem-se em um binômio que compreende, de um lado, (1) a razoabilidade da pretensão individual/social deduzida em face do Poder Público e, de outro, (2) a existência de disponibilidade financeira do Estado para tornar efetivas as prestações positivas dele reclamadas. Desnecessário acentuar-se, considerado o encargo governamental de tornar efetiva a aplicação dos direitos econômicos, sociais e culturais, que os elementos componentes do mencionado binômio (razoabilidade da pretensão + disponibilidade financeira do Estado) devem configurar-se de modo afirmativo e em situação de cumulativa ocorrência, pois, ausente qualquer desses elementos, descaracterizar-se-á a possibilidade estatal de realização prática de tais direitos (BRASIL, 2004).

Tem-se então que, no Brasil, o direito por si só não é capaz de garantir a efetividade dos direitos sociais previstos na Constituição Federal. A inexistência de recursos materiais constitui uma verdadeira barreira à efetividade desses direitos, mesmo que a situação mostrese razoável.

Diante dessas considerações, em observância ao princípio da reserva do possível, principalmente no que tange à dimensão do "financeiramente possível", levando em conta que os países subdesenvolvidos possuem dívidas externas contraídas em valores elevados ${ }^{4} \mathrm{e}$ extrema dificuldade para promover o ajuste e o equilíbrio de suas contas públicas, principalmente no atual contexto de delicada conjuntura econômica, pode-se afirmar sob essa ótica que os direitos sociais assegurados pela carta política constituem "letra morta", pois

\footnotetext{
3 Medida cautelar em arguição de descumprimento de preceito fundamental. Medida prevista na Lei Federal 9.882/99. Em seu art. $5^{\circ}, \S 3^{\circ}$ dispõe que “A liminar poderá consistir na determinação de que juízes e tribunais suspendam o andamento de processo ou os efeitos de decisões judiciais, ou de qualquer outra medida que apresente relação com a matéria objeto da arguição de descumprimento de preceito fundamental, salvo se decorrente da coisa julgada".

4 A título de exemplo, no Brasil, o estoque de dívida externa bruta estimado para abril de 2017 totalizou US\$319,7 bilhões. Banco Central do Brasil. Nota para a imprensa de 23 de maio de 2017. Disponível em $<$ https://www.bcb.gov.br/htms/notecon1-p.asp>. Acesso em 06 de junho de 2017.

5 Algo que foi escrito na lei da nação, porém está esquecido, ignorado ou também pode não haver o conhecimento do cidadão.
} 
desconhece-se momento histórico em que houve recurso financeiro suficiente para assegurálos aos cidadãos.

Nesse sentido, Kelsen (2009, p. 1-40) pontuava que os direitos sociais constituem um mero "dever ser" do Estado, vez que no campo do "ser" podem tão somente ser observados como um objetivo ou sonho a ser alcançado. ${ }^{6}$

Não bastasse isso, tem-se ainda que boa parte da população nos países subdesenvolvidos, como no caso do Brasil, vive abaixo da linha da pobreza.

No Brasil, estima-se que $4,2 \%$ da população vive abaixo da linha da pobreza. O Banco Mundial afirma que no cenário mais otimista prevê-se um aumento em 2017 de 8,7\% para 9,8\% na proporção de pessoas pobres (considerando uma linha de pobreza de 140 reais/mês), representando um acréscimo de 2,5 milhões de pessoas. Segundo essa instituição (BIRD), conforme documento divulgado em 13 de fevereiro de 2017,

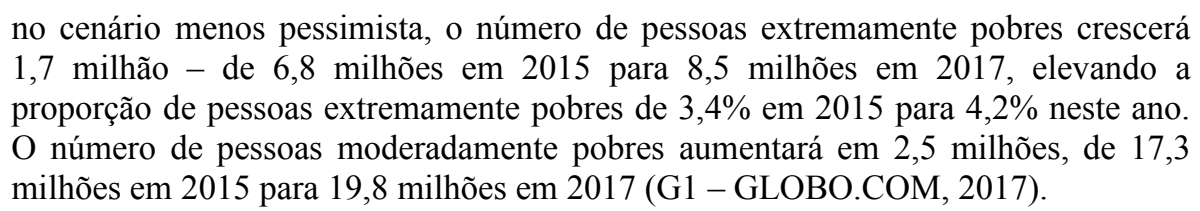

Certo é que, nessas condições, as pessoas não possuem assegurados seus direitos sociais nos termos previstos no art. $6^{\circ}$ da Constituição Federal, a saber: saúde, alimentação, trabalho, moradia, transporte, lazer, segurança, previdência social, proteção à maternidade e à infância e assistência aos desamparados.

E é por meio do princípio da reserva do possível que o Estado encontra amparo em seu sistema jurídico para não observar a concretude desses direitos.

Diante desta realidade, o investimento em capital humano mostra-se como alternativa para o alcance dos direitos sociais, o que, ilusoriamente, pode ser alcançado por meio de melhorias no desempenho das organizações e, de forma concreta, através do desenvolvimento da atividade empreendedora, conforme será demonstrado a seguir.

\footnotetext{
${ }^{6}$ Em sua "Teoria pura do direito", Kelsen traça uma distinção entre "ser" e "dever-ser", referindo-se às coisas como são e como devem ser, que desempenha dois papéis distintos, na sua concepção do Direito: (i) Em primeiro lugar, a distinção serve para diferenciar entre duas modalidades de estudo do direito: do direito como ele é e do direito como ele deve ser; (ii) Em segundo lugar, a distinção serve para diferenciar entre o mundo dos fatos, relacionado ao ser, e o mundo das normas, relacionado ao dever-ser.
} 


\section{A TEORIA DO CAPITAL HUMANO}

A teoria do capital humano surge para o mundo por meio das ideias dos pensadores da Escola de Chicago, mais especificamente os economistas Theodore W. Schultz e Gary Becker. Essa Escola possui tradição no uso de ferramentas econômicas para estudar uma grande variedade de comportamentos humanos, como: aspectos familiares que envolvem casamento e natalidade, criminalidade, discriminação, corrupção, entre outros.

$\mathrm{Na}$ esteira desses estudos econômicos, passou-se a cultivar a ideia de que é possível que o indivíduo exerça investimentos em si mesmo, de diversas formas, não só para aproveitar o presente, mas também para obter resultados futuros, pecuniários ou não.

Tal propositura passa a fazer parte da embrionária teoria do capital humano, pois começam a ser promovidos sobre a possibilidade de colher retorno sobre os investimentos feitos nas pessoas, na tentativa de mensurá-lo e comprovar sua efetividade.

Referida teoria vai além, relacionando o investimento nas pessoas à liberdade que elas podem conquistar, vez que passam a ter maior capacidade de escolha em função do incremento intelectual que reflete na qualificação para as mais diversas atividades, sejam profissionais ou mesmo relacionadas ao seu dia a dia.

Nas palavras de Schultz (1971, p. 33), "ao investirem em si mesmas, as pessoas podem ampliar o raio de escolha posto à disposição. Esta é uma das maneiras por que os homens livres podem aumentar o seu bem-estar".

Sendo assim, tratando-se de investimento, surge a necessidade de tecer diferenciação entre o capital convencional (mensurável e tangível) e o capital humano (intangível), que se mostra independente deste e capaz de apresentar retornos imensuráveis aos indivíduos, organizações e nações.

Essa ideia passou a ser primeiramente desenvolvida por Theodore Schultz a partir da década de 60, ao realizar pesquisas que resultaram na conclusão de que para estudar o investimento no homem, um novo conceito de capital era necessário. Não era mais possível considerar como capital apenas os equipamentos físicos.

Nesse aspecto, chama a atenção de Schultz (1971, p. 31) a forma pela qual países desenvolvidos, como Alemanha e Japão, conseguiram reconstruir sua economia em tão pouco tempo, mesmo após a segunda grande guerra que dilacerou os meios de produção, ou seja, o capital tangível, sendo certo que essa situação somente pode ser explicada por meio da Teoria do Capital Humano. Segundo ele, 
Embora seja óbvio que as pessoas adquiram capacidades úteis e conhecimentos, não é óbvio que essas capacidades e esses conhecimentos sejam uma forma de capital, que esse capital seja, em parte substancial, um produto do investimento deliberado, que têm-se desenvolvido no seio das sociedades ocidentais a um índice muito mais rápido do que o capital convencional (não-humano), e que o seu crescimento pode muito bem ser a característica mais singular do sistema econômico. Observou-se amplamente que os aumentos ocorridos na produção nacional têm sido amplamente comparados aos acréscimos de terra, de homens-hora e de capital físico reproduzível. O investimento do capital humano talvez seja a explicação mais consentânea para esta assinalada diferença.

A teoria sobre o capital humano foi reconhecida em 1979, oportunidade na qual ganhou o prêmio Nobel de economia em função de pesquisa com ênfase no desenvolvimento econômico, com especiais considerações em relação aos problemas dos países subdesenvolvidos. Concluiu que a educação é responsável por grande parte da melhoria da qualidade de vida das pessoas nesses países (NOBELPRIZE.ORG, 2017).

Sob o argumento de que a qualidade de vida é um recurso escasso, atribuiu a ela um valor econômico, de forma a concluir que sua aquisição resulta em custos, que são justamente o investimento em capital humano, ou seja, o investimento que as pessoas fazem em si mesmas, esclarecendo que o direcionamento de recursos em direção ao desenvolvimento delas contribui para o alcance de melhor qualidade, o que resulta na solução de grande parte de seus problemas, principalmente em relação aos países subdesenvolvidos.

Esclarece que o investimento em educação proporciona o aumento da renda das pessoas, mesmo após a exclusão dos custos diretos e indiretos em escolaridade.

Dando sequência à teoria oficialmente inaugurada por Schultz, o economista Gary Becker também trouxe importantes contribuições no bojo da Escola de Chicago, aprofundando estudos na área da economia da família (NOBELPRIZE.ORG, 2017).

Becker desenvolveu um método de análise que enfatizava a abordagem econômica ao comportamento humano, com o intuito de explicar este comportamento de forma simplificada, analisando as escolhas individuais em função da maximização de sua utilidade.

No que tange ao capital humano, vislumbrou seu desenvolvimento teórico em torno da taxa de retorno do investimento, calculando-o em relação aos ganhos em valor presente.

Nesse contexto, visualizava os rendimentos do trabalho como dividendos sobre os investimentos históricos que as pessoas faziam em si mesmas, entendendo estes como casos particulares de acumulação de capital. Seus estudos apontavam que a teoria do capital humano seria capaz de proporcionar fonte permanente de renda e riqueza, tendo em vista o seu foco no desenvolvimento de competências das pessoas e capacidade de ganho ao longo de toda sua vida. 
A teoria sobre o capital humano apontava que o investimento em educação contribui para o crescimento econômico, proporcionando melhoria nos rendimentos individuais, refletindo positivamente sobre a saúde e a formação das famílias, motivo pelo qual entende essencial que o Estado trace planos que coloque a educação ao alcance de todos (BECKER, 1964, p. 11).

Atualmente, os economistas americanos Arthur Sullivan e Steven Sheffrin definem o capital humano como

o conjunto de capacidades, conhecimentos, competências e atributos de personalidade que favorecem a realização de trabalho de modo a produzir valor econômico. São os atributos adquiridos por um trabalhador por meio da educação, perícia e experiência (SULLIVAN; SHEFFRIN, 2007, p. 5).

Nesse sentido, demonstrar-se-á como o capital humano possibilita o crescimento econômico das organizações e das próprias pessoas, apontando que através do empreendedorismo é possível alcançar os direitos sociais, que são tão distantes, considerando as condições atuais conferidas pelo Estado aos seus cidadãos.

\section{CAPITAL HUMANO NAS ORGANIZAÇÕES}

Partindo da ideia da teoria do capital humano, já na década de 80, Peter Drucker contextualizava o conceito de sociedade do conhecimento, sociedade esta baseada no conhecimento dos trabalhadores qualificados, que resultaria no recurso fundamental e diferenciador das organizações. Segundo ele

a típica empresa (do futuro) será baseada no conhecimento, uma organização composta essencialmente por especialistas que dirigem e disciplinam seu próprio desempenho de acordo com o feedback de colegas, clientes e do comando. Por isso, será o que eu chamo de organização baseada na informação (DRUCKER, 1988, p. 3).

Dessa forma, nos dias atuais, o modo de considerar a valorização de uma empresa vai muito além dos elementos que constituem seu ativo, diferentemente do que ocorria há algum tempo; outros elementos passaram a ser considerados patrimônios da organização, mesmo sendo intangíveis, como o capital intelectual, que passou a integrar o patrimônio da empresa.

A principal fonte do capital intelectual é o conhecimento organizacional, ou seja, seu capital humano, que pode ser considerado como uma ferramenta de estratégia competitiva junto à concorrência. 
A competitividade das empresas passou a ser determinada pelo conhecimento que seus recursos humanos podem influenciar no segmento em que atua, sobressaindo-se à concorrência. Assim, essa condição passou a ser fundamental pelo fato de que outros elementos estratégicos, como preço, qualidade, entre outros, já não têm tanta distinção entre as empresas. O capital intelectual veio acrescentar à valoração da empresa, sendo acrescido inclusive como valor contábil em seu patrimônio.

Complementa Peter Drucker (2008, p. 161) afirmando que

[...] na sociedade do conhecimento, o verdadeiro investimento se dá cada vez menos em máquinas e ferramentas e mais no conhecimento do trabalhador. Sem este conhecimento, as máquinas são improdutivas, por mais avançadas e sofisticadas que sejam.

Pode-se afirmar então que há uma transição em relação às teorias dos capitais das organizações. Segundo Idalberto Chiavenato (2008, p. 52), em toda a era industrial as organizações que se destacavam eram aquelas que aumentavam o capital financeiro, tangível, que refletia em seu crescimento e expansão. O sucesso era representado pelo tamanho da organização e suas instalações físicas, patrimônio e riqueza financeira. A acumulação de recursos financeiros e materiais era um dos objetivos organizacionais mais importantes. Todavia, essa conjuntura não condiz mais com a atual realidade.

Hoje, para que as organizações tenham sucesso e mantenham-se no mercado precisam ser ágeis e inovadoras, e para tanto o capital físico não é mais tão determinante. O diferencial preponderante está em sua capacidade de produzir produtos e serviços inovadores, o que certamente resulta da criatividade de seus trabalhadores.

Nessa esteira, o capital tangível está deixando de ser o recurso mais importante das organizações, cedendo espaço para os ativos intangíveis e invisíveis, denominado capital intelectual.

Karl Sveiby (1988, p. 11) pontua que esse capital intelectual presente nas organizações é constituído por capital interno, capital externo e capital humano, definindo-os da seguinte maneira:

1. Capital interno: envolve a estrutura interna da organização, conceitos, modelos e sistemas administrativos e de computação. A estrutura interna e as pessoas constituem juntas o que geralmente chamamos de organização. 
2. Capital externo: envolve a estrutura externa da organização, ou seja, as relações com clientes e fornecedores, bem como marcas, marcas registradas, patentes e a reputação ou imagem da empresa.

3. Capital humano: é o capital de gente, de talentos e de competências. A competência de uma pessoa envolve a capacidade de agir em diversas situações, tanto para criar ativos tangíveis, como intangíveis. [...] Assim, o capital humano é basicamente construído de talentos e competências das pessoas. Sua plena utilização requer uma estrutura organizacional adequada e uma cultura democrática e impulsionadora.

Esse capital humano contido nas organizações nada mais é do que aquele construído por Schultz, na década de 60, como sendo o investimento que a pessoa faz em si mesma, todavia com a peculiaridade de que esse investimento pode já ter sido efetivado no passado pela própria pessoa, ou resultar de investimentos feitos pela própria organização, com o intuito de qualificação de seu trabalhador para que produza mais a seu favor.

Certo é que esse capital humano é o grande responsável pelo desenvolvimento das organizações e das nações, resultando no aumento de produtividade das empresas e do Produto Interno Bruto dos países.

Entretanto, o que não é certo é que essa produtividade e aumento do PIB refletem no bem-estar social e no proveito das pessoas. Isso porque o capital humano trabalhando em favor das organizações, e não do próprio indivíduo, certamente gerará resultados positivos a favor de quem detém o controle daquelas, o que não necessariamente resultará em melhoria de condições para os trabalhadores.

Nos países subdesenvolvidos, como é o caso do Brasil, a concentração de renda encontra-se nas mãos dos poucos que ocupam o topo da pirâmide social, em contraponto à esmagadora maioria situada na base da pirâmide, que detém a menor parte da renda do que é produzido na nação.

Desta forma, quando se tem o capital humano participando ativamente das organizações, produzindo resultados diferenciados e gerando seu crescimento, tal situação não necessariamente resultará em melhoria no Índice de Desenvolvimento Humano - $\mathrm{IDH}^{7}$, nem no Coeficiente de $\mathrm{Gini}^{8}$, segundo o qual, no ano de 2014, o Brasil apresentava o número de

\footnotetext{
7 Uma medida importante concebida pela ONU (Organização das Nações Unidas) para avaliar a qualidade de vida e o desenvolvimento econômico de uma população.

${ }^{8}$ O coeficiente de Gini (ou índice de Gini) é um cálculo usado para medir a desigualdade social, desenvolvido pelo estatístico italiano Corrado Gini, em 1912. Apresenta dados entre o número 0 e o número 1 , onde zero (0)
} 
$0,49^{9}$, colocando-se atrás de países como Guatemala e Angola, vez que a riqueza produzida é revertida em favor daqueles poucos que exercem o controle das organizações, gerando melhorias no PIB do país, trazendo uma aparência fictícia de melhoria no bem-estar da população.

Diante desse cenário, percebe-se que a aplicação do capital humano para o desenvolvimento das organizações está longe de garantir o alcance dos direitos sociais para a população.

\section{EMPREENDEDORISMO COMO FORMA DE ALCANCE DOS DIREITOS}

\section{SOCIAIS}

O estudo do empreendedorismo ganha a cada dia mais espaço nas pesquisas científicas devido ao seu potencial de ação sobre o desenvolvimento econômico e social que proporciona, bem como ao bem-estar levado à coletividade em função do desenvolvimento de ideias inovadoras.

O empreendedorismo retrata a materialização da teoria do capital humano, de forma que os indivíduos, por meio do conhecimento acumulado por toda sua vida, buscam o desenvolvimento de ideias inovadoras que podem proporcionar o desenvolvimento econômico e melhores condições de vida para si, e também para a população, esta que usufruirá do resultado de seus empreendimentos.

$\mathrm{Na}$ década de 60, Schumpeter (1961, p. 110) já abordava a questão do empreendedorismo, suscitando que o homem de negócios, ou empreendedor, seria o "impulso fundamental que põe e mantém em funcionamento a máquina capitalista que procede dos novos bens de consumo, dos novos métodos de produção [...] criados pela empresa capitalista".

\footnotetext{
corresponde a uma completa igualdade na renda (onde todos detêm a mesma renda per capta) e um (1), que corresponde a uma completa desigualdade entre as rendas (onde um indivíduo, ou uma pequena parcela de uma população, detém toda a renda e os demais nada têm). Gini mede o coeficiente através de pontos percentuais (que é igual ao coeficiente multiplicado por 100).

${ }^{9}$ BRASIL. Secretaria da Receita Federal do Brasil. Disponível em <http://www.fazenda.gov.br/noticias/2016/maio/200bspe-divulga-relatorio-sobre-a-distribuicao-da-renda-nobrasil>. Acesso em 04 de junho de 2017.
} 
Segundo Dornelas (2005, p. 39), empreendedorismo é o envolvimento de pessoas e processos que, em conjunto, levam a transformação de ideias em oportunidades. Acrescenta que a perfeita implementação destas oportunidades leva à criação de negócios de sucesso.

Fernando Dolabela e Marco Gorini (2016, p. 7) destacam a liberdade que o empreendedorismo pode conferir ao indivíduo, afirmando que, à medida que uma pessoa se desenvolve, ela alcança maior grau de liberdade em relação ao entorno, em relação à sua intervenção no mundo, e aprende a realizar melhores escolhas. $\mathrm{O}$ desenvolvimento e o empoderamento do indivíduo são pressupostos ao desenvolvimento de sua empresa. Empresa e indivíduo formam um só conjunto, são indissociáveis. Ao se desenvolver, o indivíduo desenvolve sua empresa.

Os mesmos autores propõem que a atividade empreendedora pode ser desenvolvida em qualquer área, referindo-se a alguém que sonha e busca transformar o seu sonho em realidade. Essa concepção abrange todos os tipos de empreendedores, dedicados a qualquer atividade. Sua teoria aborda o empreendedor como uma forma de ser, podendo estar presente em qualquer atividade humana.

Hisrich e Peter (2004, p. 33) afirmam que "a atividade empreendedora envolve esforços para mudanças na estrutura dos negócios e da sociedade, não ficando circunscrita apenas ao aumento de produção e renda per capita".

Verifica-se por meio do pensamento dos autores mencionados que o empreendedorismo é um meio transformador, capaz de gerar mudanças que refletem nas próprias pessoas que o praticam, possibilitando-lhes melhor posicionamento dentro da sociedade, chegando a atingilas como um todo, esta que pode beneficiar-se das inovações implementadas, bem como pelo próprio aquecimento da economia que resultará em desenvolvimento para a nação.

Isso porque a atividade empreendedora está ao alcance de todos, sem restrições ou discriminações para o seu desenvolvimento.

É na esteira desse entendimento que Dolabela apresenta a ideia de que a atividade empreendedora transforma conhecimento e sonho em riqueza, enaltecendo que seu desenvolvimento gera valor para quem o pratica, mas muito mais para a coletividade.

Em função disso, vislumbra a essencialidade da prática da atividade empreendedora para o desenvolvimento de toda a sociedade, bem como para a geração de maior igualdade social entre as pessoas, o que viabilizaria o alcance dos direitos sociais por todos.

Destaca então que é por meio da educação, por meio do desenvolvimento do capital humano de cada indivíduo, que a atividade empreendedora pode prosperar, motivo pelo qual o 
autor desenvolve a teoria da pedagogia empreendedora, através da qual afirma que educar é preparar as pessoas para construírem seu próprio caminho.

Nesse sentido, Delors (2001, p. 100) também traz o entendimento de que a educação é o meio para que as pessoas construam o seu próprio destino, tendo como papel essencial "conferir a todos os seres humanos a liberdade de pensamento, discernimento, sentidos e imaginação de que necessitam para desenvolver os seus talentos e permanecerem, tanto quanto possível, donos de seu próprio destino".

Assim, o objeto da teoria da pedagogia empreendedora consiste na preparação, principalmente dos jovens, mas também dos adultos, no sentido de possibilitar-lhes o exercício do empreendedorismo como forma de alcançar a liberdade, a subsistência e o alcance dos direitos sociais. Busca pelo viés da educação escolar atribuir capacidades individuais de autoemprego.

Essa preparação é necessária, tendo em vista que a cultura atual de nossa sociedade leva os indivíduos a um estado de dependência, que os priva de fazer escolhas de maior complexidade, vez que se preparam durante toda a vida para alcançarem um emprego, o que os torna dependentes de seus empregadores e do Estado.

Nesse sentido, essa cultura de dependência deve ser revista, haja vista que, nas palavras de Dolabela (2003, p. 23),

o emprego (forma de relação dependente) e o know-how (conteúdo), que constituíram o paradigma das relações de trabalho nos últimos dois séculos, são substituídos na era da velocidade e da informação em tempo real por um outro modelo - o da capacidade de gerar novos conhecimentos e identificar oportunidades (conteúdos), em uma relação de interdependência (autonomia relativa), sob a forma empreendedora.

Deve-se então promover uma mudança da cultura do emprego, preparando as pessoas para que assumam um papel empreendedor que lhes possibilite maior liberdade e o alcance dos direitos sociais por si mesmas, o que deve ser trabalhado desde a educação de base.

Dolabela (2003, p. 51) afirma que "a essência da estratégia pedagógica está em movimentar o ciclo sonhar e buscar realizar o sonho". O sonho assume papel estruturante quando possui energia para incentivar o indivíduo a tentar realizá-lo. Propõe então uma metodologia capaz de moldar a mente das crianças, jovens e adultos para que busquem a criatividade, a autonomia e a liberdade. A pedagogia empreendedora vai se dedicar principalmente à conexão entre o sonho e a sua realização (DOLABELA, 2003, p. 53). 
É por meio dessa teoria do empreendedorismo, principalmente no que tange à pedagogia empreendedora, que se constrói um cenário em que a preparação dos indivíduos para o desenvolvimento dessa atividade pode proporcionar-lhes o alcance dos direitos sociais, que no atual contexto, não é garantido pelo Estado.

Assim, tendo por subsídio referida teoria, abre-se um caminho para que o Estado, por meio de investimentos em capital humano, tendo por escopo a pedagogia empreendedora, proporcione aos seus cidadãos a possibilidade de terem acesso aos direitos sociais, vez que as prestações positivas que poderiam refletir na garantia e efetivação de cada um desses direitos esbarram na reserva do "financeiramente possível".

\section{CONCLUSÃO}

Ao incluir na Constituição Federal de 1988 os direitos sociais, o constituinte impôs ao Estado várias obrigações de caráter positivo, com a finalidade de assegurar aos cidadãos a condição de igualdade e dignidade da pessoa humana.

Todavia, referidos direitos sociais somente podem ser assegurados com a existência de recursos financeiros, vez que envolvem prestações positivas do Estado, motivo pelo qual o ordenamento jurídico acatou a teoria da reserva do possível, que possibilita a entrega dos direitos sociais apenas se concebidos por razoáveis e de acordo com a disponibilidade de recursos financeiros.

Os direitos sociais encontram barreiras para a sua efetivação, tornando-se inviáveis para grande parte da população, vez que o Estado nunca foi detentor de recursos financeiros suficientes para proporcionar dignidade a todos, indiscriminadamente.

Por meio da teoria do capital humano verificou-se a possibilidade de conferir às pessoas o alcance aos direitos sociais através de seus próprios méritos, tendo em vista que, por meio de investimentos em si mesmas, podem recolocarem-se na sociedade.

Entretanto, esse capital humano, quando investido nas organizações, não gera o efeito de afastar as desigualdades sociais, vez que proporciona riquezas para as próprias organizações e à nação, mas não é suficiente para proporcionar distribuição equânime dos valores produzidos, mantendo-os nas mãos dos poucos que detêm o controle.

O empreendedorismo é a melhor maneira para que as pessoas tenham acesso aos direitos sociais, utilizando-se da teoria do capital humano, para que, através da educação, haja qualificação dos indivíduos, o que é capaz de viabilizar o desenvolvimento de suas próprias 
atividades e proporcionar o alcance à liberdade, resultando na igualdade e dignidade para todos.

A teoria do capital humano, aplicada no contexto da pedagogia empreendedora, propõe direcionamento de esforços do Estado para a educação e formação das pessoas, com o intuito de que seja criada uma cultura empreendedora, capaz de colocar todos em um patamar de igualdade de condições, proporcionando autonomia e liberdade de escolha para o desenvolvimento de suas próprias atividades, o que possibilita a concretização dos direitos sociais por meio dos esforços de cada um.

\section{REFERÊNCIAS}

ALMEIDA, Luiz Eduardo Lemos de; MARTINS, Plínio Lacerda. Cidadania ativa na outorga de concessão de serviço público. Revista da Faculdade de Direito da UFRGS, Porto Alegre, n. 35 , p. 85-98, dez. 2016.

ARAUJO, Luiz Alberto David. NUNES JÚNIOR, Vidal Serrano. Curso de Direito Constitucional. São Paulo: Saraiva, 1999.

BECKER, Gary Stanley. Human capital: a theoretical and empirical analysis with special reference to education. Chicago: The University of Chicago Press, 1964.

BRASIL. Banco Central do Brasil. Nota para a imprensa de 23 de maio de 2017. Disponível em $<$ https://www.bcb.gov.br/htms/notecon1-p.asp>. Acesso em 06 de junho de 2017.

BRASIL. Constituição da República Federativa do Brasil de 1988. Disponível em $<$ http://www.planalto.gov.br/ccivil_03/constituicao/constituicaocompilado.htm>. Acesso em 04 de junho de 2017.

BRASIL. Receita Federal do Brasil. Relatório sobre a distribuição de renda no Brasil. 2016. Disponível em <http://www.fazenda.gov.br/noticias/2016/maio/200bspe-divulga-relatoriosobre-a-distribuicao-da-renda-no-brasil>. Acesso em 04 de junho de 2017.

BRASIL. Supremo Tribunal Federal. ADPF 45 MC/DF. Medida cautelar em arguição de descumprimento de preceito fundamental. Rel. Min. Celso de Mello. Julgamento: 29/04/2004. Disponível em <https://stf.jusbrasil.com.br/jurisprudencia/14800508/medida-cautelar-emarguicao-de-descumprimento-de-preceito-fundamental-adpf-45-df-stf $>$. Acesso em $08 \mathrm{de}$ junho de 2017.

CHIAVENATO, Idalberto. Recursos Humanos: o capital humano das organizações. São Paulo: Atlas, 2008.

DALLARI, Dalmo de Abreu. Direitos Humanos e Cidadania. SãoPaulo: Moderna, 2004.

DELORS, Jacques. Educação: um tesouro a descobrir. São Paulo: Cortez, 2001. 
DOLABELA, Fernando. GORINI, Marco. Empreendedorismo na base da pirâmide: a história de um intraempreendedor, desafios e aprendizados. Rio de Janeiro: Alta Books, 2016.

DOLABELA, Fernando. Pedagogia Empreendedora. São Paulo: Editora Cultura, 2003.

DOLABELA, Fernando. Pedagogia empreendedora: o ensino de empreendedorismo na educação básica, voltado para o desenvolvimento social e sustentável. São Paulo: Sextante, 2003.

DORNELAS, José Carlos Assis. Empreendedorismo: Transformando Idéias em Negócios. Rio de Janeiro: Campus, 2005.

DRUCKER, P. F. Administrando em tempos de grandes mudanças. Tradução de Nivaldo Montinguelli Jr. São Paulo: Pioneira, 2008.

DRUCKER, P. F. The Coming of The New Organization. Harvard Business Review, Boston, Reprint Number, p. 3 - 11, January - February, 1988. Disponível em $<$ https://hbr.org/1988/01/ the-coming-of-the-new-organization>. Acesso em 08 de junho de 2017.

FERCOT, Céline. The Improbable Justiciability of Social Rights in Germany and Switzerland. In EUI Working Papers: Diversity of social rights in Europe, rights of the poor, the poor rights. Law 2010/07. University Paris, Oueste Natenrre - European University Institute Social Law Working Group. Fls. 71/94. Disponível em $<$ http://cadmus.eui.eu/bitstream/handle/1814/14739/LAW_2010_07.pdf $>$. Acesso em 15 de junho de 2017.

G1 - GLOBO.COM. Versão on line. Brasil terá até 3,6 milhões de 'novos pobres' em 2017, diz Bird: Instituição afirma que crise econômica ameaça redução da pobreza e recomenda aumento do orçamento do Bolsa Família para $\mathrm{R} \$ 30,4$ bilhões para conter avanço da miséria. Por Deutsche Welle. 13.02.2017. Disponível em $<$ http://g1.globo.com/economia/noticia/brasil-tera-ate-36-milhoes-de-novos-pobres-em-2017diz-bird.ghtml>. Acesso em 06 de junho de 2016.

HISRICH, R. D. PETER, M. P. Empreendedorismo. Porto Alegre: Bookman, 2004.

KELSEN, Hans. Teoria Pura do Direito. São Paulo: Martins Fontes, 2009.

KRELL, Andreas Joachim. Direitos Sociais e Controle Judicial no Brasil e na Alemanha: os (des)caminhos de um direito constitucional comparado. Porto Alegre: Sergio Antonio Fabris Editor, 2002.

LEAL, Márcio Flávio Mafra. Ações coletivas: história, teoria e prática. Porto Alegre: Sergio Antonio Fabris Editor, 1998.

NOBELPRIZE.ORG. The Official Web Site of the Nobel Prize. Biography of Gary Stanley Becker.

Disponível

em

$<$ http://www.nobelprize.org/nobel_prizes/economic-sciences/laureates/1992/becker-

bio.html>. Acesso em 15 de junho de 2017. 
NOBELPRIZE.ORG. The Official Web Site of the Nobel Prize. Biography of Theodore W. Schultz.

Disponível

em

$<$ http://www.nobelprize.org/nobel_prizes/economic-sciences/laureates/1979/schultz-

bio.html>. Acesso em 15 de junho de 2017.

SARLET, Ingo Wolfgang. A Eficácia dos Direitos Fundamentais. Porto Alegre: Livraria do Advogado, 2008.

SARLET, Ingo Wolfgang. A Eficácia Horizontal dos Direitos Fundamentais: uma teoria geral dos direitos fundamentais na perspectiva constitucional. Porto Alegre: Livraria do Advogado, 2009.

SCHULTZ, Theodore W. O Capital Humano: Investimentos em Educação e Pesquisa. Zahar Editores, Rio de Janeiro, 1971.

SCHUMPETER, Joseph Alois. Capitalismo, Socialismo e Democracia. Rio de janeiro: Fundo de Cultura, 1961.

SILVA, José Afonso da. Curso de Direito Constitucional Positivo. São Paulo: Malheiros Editores, 2000.

SULLIVAN, Arthur; SHEFFRIN, Steven M. Economics: Principles in action. Upper Saddle River, New Jersey: Pearson Prentice Hall, 2007.

SVEIBY, Karl Erik. A nova riqueza das organizações: gerenciando e avaliando patrimônios de conhecimento. Rio de Janeiro: Campus, 1988.

\section{DADOS DA PUBLICAÇÃO}

Categoria: artigo submetido ao double-blind review.

Recebido em: 21/10/2017.

Aceito em: 30/06/2019. 
